\section{FAST, BRILLIANT POLISHING}

Among their extensive range of abrasives, Shofu manufacture Dura-Green stones. These are made from silicon carbide grit for fast contouring and finishing of porcelain, composite precious alloys and amalgam.

Dura-White stones are for finishing of porcelain, composite precious alloys and amalgam. Brownie, Greenie and Supergreenie silicone polishers are for fast, brilliant polishing on precious metals and amalgam; and the Super-
Snap finishing and polishing disc system is for all microfilled and hybrid composite fillings.

One Gloss unique one-step finisher and polisher can be used to finish and polish all composite restorations by altering the contact pressure on the restoration, without having to change instrument.

Shofu have produced a catalogue on their range of abrasives so that customers can see at a glance the most appropriate rotary instrument for the job in hand.

\section{Reader response number 62}

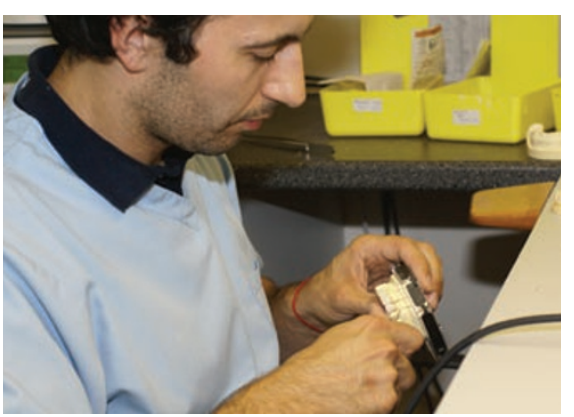

- A flexible service and the ability to turn work around quickly.

CosTech Elite's GDC-registered managers guarantee a seven-day turnaround on the Elite7 service (subject to availability) with excellent customer care. Reader response number 63

\title{
NEW ICE GUMS CONTAIN XYLITOL
}

The Wrigley Company is launching three new products in their range of sugar-free chewing gum: Extra Ice Peppermint, Extra Ice Spearmint and Extra Ice White.

All three of the new products contain 50\% xylitol and along with Orbit Complete - which is also included in the oral care range - have been accredited by the British Dental Health Foundation.

As well as the widely recognised benefits of sugar-free gum on the production of saliva, xylitol is an ingredient with proven dental benefits including preventing plaque formation, which gives it a unique role in preventive strategies for dental health.

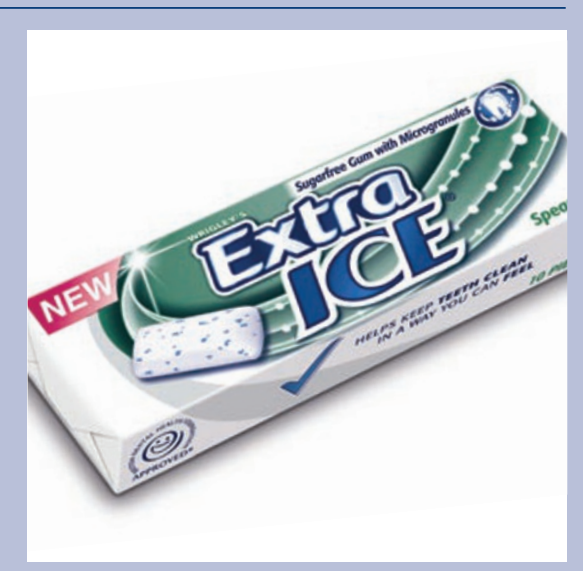

Chewing sugar-free gum helps to neutralise plaque acid and maintain tooth mineralisation.

Reader response number 64

\section{EXTRAORDINARY BOND}

The recently launched RelyX Unicem 2 Automix self-adhesive resin cement from 3M ESPE offers users the benefits of even simpler application due to its new automix syringe and custom application tips.

This new syringe delivery cement is also suitable for permanent cementation of all-ceramic, composite or metal inlays, onlays, crowns and bridges as well as posts and screws.

The syringe extrudes the readymixed cement through mixing tips which are available in different sizes: regular tips for standard applications; endo tips ensuring a safe and voidfree procedure when working in the root canal; and intra-oral tips for the cementation of inlays and onlays.

RelyX Unicem 2 Automix cement combines ease of use with strength and aesthetics, has high colour stability, extraordinary bond strength and great moisture tolerance.

Reader response number 65

\section{AN EXCELLENT LEARNING PORTAL}

The website www.dentinaltubules. com is designed for those who have a passion for learning and sharing knowledge.

www.dentinaltubules.com was set up in 2009 and has amassed nearly 3,500 members from the global dental community. Over 400 dental articles have been published in just 15 months and now, the team at dentinaltubules plan to provide even more services for its members with major developments this February.

Website creator Dhru Shah set out to establish a dental resource that everyone in dentistry can use; an excellent learning portal for the whole dental team. www. dentinaltubules.com plans to be THE dental resource.

The website is free to sign up to and it is also free to access articles.

Reader response number 66 